\title{
Nutrition knowledge, attitudes and practices among healthcare workers in management of chronic kidney diseases in selected hospitals in Dar es Salaam, Tanzania; a cross-sectional study
}

\author{
Adeline E. Munuo ${ }^{1 *}$, Beatrice W. Mugendi², Onesmo A. Kisanga ${ }^{3}$ and George O. Otieno ${ }^{4}$
}

\begin{abstract}
Background: Chronic kidney disease (CKD) is a global public health problem. All health care professionals need to be knowledgeable and competent in nutrition as it applies to health promotion, prevention and treatment of acute and chronic diseases. Nutrition intervention is an important component in optimizing diet among CKD patients. However, there is limited information on the nutrition knowledge on management of CKD among healthcare workers in Dar es Salaam Tanzania. This study assessed nutrition knowledge, attitudes and current practices of healthcare workers in management of patients with CKD in selected hospitals.
\end{abstract}

Methods: This cross sectional study was conducted amongst 133 healthcare workers in renal units in selected hospitals from December 2011 to March 2012. Hospitals were purposively selected based on the availability of renal care services in the facility. Nutrition knowledge and practices were assessed using a standardized questionnaire. Knowledge levels were categorised as > $61 \%$ "adequate" $41-60 \%$ "moderate" and 1-40\% "low". Attitudes were measured using a 5 Likert scale. Descriptive statistics were used to summarize data. Chi-square was used to test the relationship between categorical variables. A $p$-value of $<0.05$ was considered statistically significant.

Results: The mean nutrition knowledge score among health care workers was 9.8 (SD 3.12). There was a significant difference in the nutrition knowledge among carders ( $p \leq 0.001$ ). Medical specialists had a higher mean score (13.75) compared to medical doctors and nurses with mean scores 12.05 and 9.51 respectively. Other cadres had lower mean score of 8.65. Likert scale showed that $94 \%$ had positive attitudes on the role of nutrition in preventing and treating diseases. Most of respondents (92\%) did not use any nutrition guidelines. Nutrition management were discussed occasionally during ward rounds. There were significant relationship between age group $\left(x^{2}=16.69 ; p=0.01\right)$, work experience $\left(x^{2}=18.61 ; p<0.01\right)$ and nutrition knowledge of participants.

Conclusion: Nutrition knowledge among study participants was poor; though their attitude was positive they failed to practice due to poor knowledge. Inadequate nutrition training in medical school, lack of resources and motivation were identified as factors that influence nutrition management of CKD in the study area. Recommendations from the study include: review of medical curriculum to incorporate clinical nutrition topics, continuous nutrition education programs for in-services, improving working conditions and hiring clinical nutritionists in each hospital department would improve nutrition management of CKD patients in hospitals.

Keywords: Nutrition knowledge, Chronic kidney disease, Healthcare workers

\footnotetext{
* Correspondence: adelinemunuo@yahoo.com

${ }^{1}$ Tanzania Food and Nutrition Centre, Dar es salaam, Tanzania

Full list of author information is available at the end of the article
} 


\section{Background}

Chronic kidney disease (CKD) is a permanent and progressive loss of kidney function, which results in deterioration of renal function or End-Stage Renal Disease (ESRD). Olugbenga et al., [1] found ESRD as a devastating medical, social and economic problem for the patients, their families, and the country as a whole. The overall management of CKD focuses on medication, dialysis, transplant and nutrition. Better management of CKD can slow progression of renal dysfunction, prevent metabolic complications, and reduce cardiovascularrelated outcomes [2]. Nutrition plays a major role in the protection of renal function and well-being in the CKD patient [3]. The evidence base for practical use of nutrition-based preventive and curative interventions is rapidly growing and implementation research steadily improves delivery of best practices. There is little doubt that health professionals can be more effective in their daily practice when they draw on current nutrition knowledge and effective clinical skills [4]. Furthermore, there are numerous examples of beneficial patient outcomes resulting from nutrition practices in inpatient, outpatient, and community settings. In acute care settings, best nutrition practices have been shown to improve patient outcomes and reduce health care costs [5]. Despite the profound impact good nutrition has on health and wellness, the science of nutrition and its application to healthcare are not fully integrated in most health professions training programs. This gap is further compounded by the fact that patients and the public remain confused about the correct nutritional advice to follow given the widespread media interest attracted by diet and the disparity in nutrition-related health messages that are in circulation [6]. Information from health workers to patients has been found to have a positive and significant correlation with adoption of dietary behavior and reduced risk of nutrition related chronic disease [7]. However, ability of healthcare workers to provide accurate, practical and consistent dietary advice appropriate to the needs of patients is limited [7, 8].

As there are only few published data about nutritional knowledge of healthcare workers in Tanzania, the aim of the current study was to determine the nutrition knowledge level, attitudes and current practices of the healthcare providers working in renal units at the three hospitals in Dar es Salaam, Tanzania.

\section{Methods}

\section{Study area, design and period}

The study was conducted at Muhimbili National Hospital, Regency Medical Centre and the Aga Khan Hospitals which are all found in Dar es Salaam region, Tanzania. Dar es Salaam is located at 6 $48^{\prime}$ South, $39^{\circ} 17^{\prime}$ East on a natural harbour on the eastern coast of Africa, with sandy beaches in some areas. Administratively, the Dar es Salaam region is divided into three municipals: Ilala, Kinondoni and Temeke. It is largest city in Tanzania, with a population increase of $5.6 \%$ per year [9]. This cross sectional study was conducted from December 2011 to March 2012.

\section{Target population}

The source populations were all healthcare workers in selected hospitals in Dar e salaam region. The study populations were healthcare workers who have worked in the renal unit not less than six months and those who were found on duty on the day of data collection. Healthcare workers who were on annual or maternity leave and who graduated recently were excluded in this study.

\section{Sample and sampling procedure}

Purposive sampling was used to get the sample. A list of all healthcare workers in the renal unit /ward from selected hospitals was obtained from the head of the sections. A total of 140 participants were recruited for this study. List included 95, 25 and 20 from MNH, RMC and Aga Khan Hospital respectively.

\section{Ethical considerations}

Ethical approval was obtained from the Research and Publication Committee of Muhimbili University of Health and Allied Sciences (MUHAS), prior to data collection. Permission was taken from Hospital administrators. Written informed consent was obtained from each individual after the purpose of the study was explained. Participants were told that they had full right to participate or not, and they were also informed that all the data obtained from them would be kept confidential using codes instead of any personal identifiers.

\section{Study instrument}

A structured, self-administered questionnaire and a focus group discussion guide were used to collect data for this study. The instruments were developed following an extensive literature review guided by the objectives of the study and validated by subject experts. The questionnaire was pre-tested to determine its reliability and validity before used in the actual study.

\section{Questionnaire}

This questionnaire contained 47 items, with 7 of them targeting demographic characteristics; 40 items targeting knowledge about CKD related information including general knowledge, sources of nutrition knowledge, nutrient and their sources as well as diet related risk factors for CKD. Questions on attitudes and practices were also included. Correct answers were scored as per questionnaire sections. The knowledge score were determined by 
taking the number of correct responses by each respondent out of 30 knowledge questions asked expressed as percentage. The percentage scores were graded as: $>61$ = 'adequate'. 41-60 = "average" and 1-40 "poor". The grading system was designed by the researcher as there was no standard scoring table available in the literature.

\section{Focus group discussion guide}

A Focus group discussion guide was used to collect information that could not be collected using the questionnaire such as "challenges encountered in nutrition management of CKD patients, perception and attitude about nutrition training in medical /nursing school, and measures that can be taken to improve nutritional management of CKD patients. Three groups were made, each comprising of 10 participants these were leaders and section leaders from the selected hospital. During group discussion, the responses were tape recorded and notes were taken. Attitudes were rated using a Likert scale ranging from 1 "strongly disagree" to 5 "strongly agree".

\section{Data analysis}

Data management and analysis were performed with SPSS software version 17; Comparisons between groups (carders) were performed using one-way analysis of variance (ANOVA). Chi-square was used to test the relationship between categorical variables. A $p$-value of $<0.05$ was considered statistically significant.

\section{Results}

\section{Socio demographic data}

A Questionnaire was given to each of the 140 subjects who included 4 specialists, 21 medical doctors, 77 nurses, 9 nutritionists, 4 radiographers, 11 laboratory technicians and 7 pharmacists. Overall, 133 participants out of 140 listed completed the survey with a response rate of $95 \%$. There were $39(29.3 \%)$ males and 94 (70.7 \%) female participants in the study. Most (74.1\%) of the study participant's age ranged between 29 and 50 years.

\section{Nutrition knowledge}

More than half $(59.4 \%)$ of the participants had low nutrition knowledge. The mean nutrition knowledge score was 9.8 (SD 3.12). There was a significant difference in the nutrition knowledge among carders $(p<0.001)$. The comparison of knowledge score of respondents by their carders using Waller- Duncan technique showed that medical doctors had a mean of mean score (12.05). Medical specialists had almost the same score as medical doctors, whereas, nurse officers had a mean score of (9.51) which was statistically different from that of specialists and medical doctors.. Other cadres had lower mean score of 8.65 which was statistically different from that of medical doctors and specialists $(p<0.001)$ (Table 1$)$.

\section{CKD related nutrition knowledge}

As shown in Table 2, the results of the current study indicated that health care workers are aware of topics related to signs of fluid overload, functions of protein, recommendation to increase carbohydrate to CKD patients and reasons for fluid restrictions scoring between 53-65\%. Healthcare workers showed poor knowledge regarding other important topics in nutrition, like goals of nutrition management in CKD and importance of protein of high biological values. Table 3 showed signficant relationship between some of demographic characteristics (age $p=0.01$ and work experience $p<0.05$ ) and nutrition knowledge.

\section{Attitude and practices}

"Healthcare workers are very knowledgeable in nutrition related matters." was to determine how respondents rated their knowledge when it comes to nutrition related issues. Surprisingly, $61.7 \%$ disagreed, $26.3 \%$ were uncertain and only $12 \%$ agreed that they were knowledgeable on nutrition matters.

The significance of the statement "Do u use guidelines when discussing nutrition plan for patient with CKD." was to determine healthcare workers practices on nutrition management of patients. Most of respondents (92\%) did not use any guidelines; instead they use some

Table 1 ANOVA for comparison of nutrition knowledge score by carders and Waller Duncan statistics for homogeneous means

\begin{tabular}{lllll}
\hline & Sum of Squares & df & Mean Square & S \\
\hline Between Groups & 216.32 & 3 & 72.11 & 8.23 \\
Within Groups & 1130.05 & 129 & 8.76 & .0001 \\
Total & 1346.361 & 132 & & Mean scores \\
Waller-Duncan occupation & $\mathrm{N}$ & Subset for alpha $=0.05$ & & \\
& & Mean scores & Mean scores & \\
$\quad$ Others & 31 & 8.65 & 9.51 & 12.05 \\
$\quad$ Nurse officers & 77 & 9.51 & 12.05 & 13.75 \\
$\quad$ Medical doctors & 21 & & & \\
$\quad$ Specialists & 4 & & & \\
\hline
\end{tabular}


Table 2 The simplified form of questions asked together with the correct percentage of answers $(N=133)$

\begin{tabular}{|c|c|c|c|}
\hline No & Question & Correct answer & n (\%) \\
\hline 1. & Goals of nutritional management of chronic kidney disease & $\begin{array}{l}\text { maintain good nutritional status, slow down disease progression and treat } \\
\text { complications }\end{array}$ & $48(36.1)$ \\
\hline 2. & Signs of a patient with fluid overload & oedema, shortness of breath, hypertension & $87(65.4)$ \\
\hline 3. & Functions of protein & $\begin{array}{l}\text { repair tissue, making hormones antibodies and enzymes, balance acid-base, } \\
\text { fluid and electrolytes }\end{array}$ & $84(63.2)$ \\
\hline 4. & $\begin{array}{l}\text { Types of foods with high level of sodium patient with } \\
\text { CKD should avoid }\end{array}$ & canned and processed foods such as bacon, sausage, popcorn & $30(22.6)$ \\
\hline 5. & Why protein is restricted for a renal patient & to slow progression and minimize accumulation of uremic toxins & 26(19.5) \\
\hline 6. & $\begin{array}{l}\text { Importance of protein of high biological value for CKD } \\
\text { patient }\end{array}$ & $\begin{array}{l}\text { to provide the essential amino acids without resulting in excessive urea } \\
\text { production }\end{array}$ & 15(11.5) \\
\hline 7. & $\begin{array}{l}\text { Why it is recommended to increase carbohydrate intake } \\
\text { for a renal patient }\end{array}$ & provide energy and spare protein & $80(60.2)$ \\
\hline 8. & Why fluids are restricted for a renal patient & reduce risks of hypertension & $71(53.4)$ \\
\hline 9. & Why minerals are restricted for a renal patient & to avoid accumulation leading to bone diseases & $42(31.6)$ \\
\hline
\end{tabular}

information from patients those were from other hospitals.

"How often do you conduct nutrition education session to patient with CKD" this statement was to determine the frequency at which nutrition education sessions were

Table 3 Demographic characteristics of healthcare workers with good Knowledge on nutrition management of CKD ( $N=133)$

\begin{tabular}{|c|c|c|c|}
\hline $\begin{array}{l}\text { Demographic } \\
\text { variable }\end{array}$ & $\begin{array}{l}\text { Total no } \\
N=133\end{array}$ & $\begin{array}{l}\text { Good } \\
\text { knowledge }\end{array}$ & Significance \\
\hline & $\mathrm{n}(\%)$ & & \\
\hline \multicolumn{4}{|l|}{ Sex } \\
\hline male & $39(29.3)$ & $20(35.7)$ & $x^{2}=2.5 ; d f=2 ; p=0.285 \mathrm{NS}$ \\
\hline Female & $94(70.7)$ & $36(64.3)$ & \\
\hline \multicolumn{4}{|l|}{ Age group } \\
\hline$<28$ & $15(11.3)$ & $5(16.7)$ & \\
\hline $29-39$ & $45(33.5)$ & $9(30.0)$ & \\
\hline $40-50$ & $54(40.6)$ & $12(40.0)$ & $x^{2}=16.69 ; d f=6 ; p=0.01$ \\
\hline$>51$ & $19(14.3)$ & $4(13.3)$ & \\
\hline \multicolumn{4}{|l|}{ Occupation } \\
\hline Doctors & $21(15.8)$ & $14(25.0)$ & \\
\hline Nurses & $77(57.9)$ & $29(51.8)$ & $x^{2}=13.22 ; d f=8 ; p=0.1 \mathrm{NS}$ \\
\hline Nephrologists & $3(3)$ & $3(5.4)$ & \\
\hline Others & $32(24)$ & 10(17.9) & \\
\hline \multicolumn{4}{|l|}{ Work experience } \\
\hline \multicolumn{4}{|l|}{$>1$ year } \\
\hline $2-5$ years & $31(23.3)$ & $8(14.3)$ & \\
\hline 6-10year & $57(42.9)$ & $31(55.4)$ & $x^{2}=18.61 ; d f=6 ; p<0.05$ \\
\hline \multirow[t]{2}{*}{$<10$ years } & $23(17.3)$ & 11(19.6) & \\
\hline & $22(16.5)$ & $6(10)$ & \\
\hline
\end{tabular}

NS not significant

df degrees of freedom

$n=$ total number of health care workers interviewed () \% conducted per week at the renal unit. It was found that nutrition education was irregularly done as indicated in (Table 4).

During group discussion most of participants raised some issues seems as obstacles to good nutrition management of CKD as seen in Table 5.

\section{Discussion}

The present study revealed that, most of participants had poor nutrition knowledge. Although majority $88 \%$ of the participants had basic nutrition training in medical/nursing school, there appeared to be a number of gaps in their nutrition-related knowledge. The knowledge level of healthcare workers was found to be higher (Table 1) due to the nutrition education received and higher level of professionalism in the application of their knowledge. The increase in knowledge scores was not found to be in related with the increase in professional experience, instead healthcare workers who had fewer years of practices scored high. This could be due to current nutrition updates and their personal initiatives through reading from different sources as they mentioned their sources of nutrition knowledge.

Similar observation was explained by another evaluation study in USA where it was reported that clinical experience didn't increase the level of the nutritional

Table 4 Frequency of nutrition education sessions for CKD Patients in the study area

\begin{tabular}{lll}
\hline Nutrition session per week & $N=133$ & $\%$ \\
\hline 0 & 65 & 48.9 \\
$1-2$ & 38 & 28.6 \\
Others $^{\mathrm{a}}$ & 30 & 22.6 \\
Total & 133 & 100 \\
\hline
\end{tabular}

${ }^{a}$ Not scheduled 
Table 5 Themes and findings emerged from focus group discussion

\begin{tabular}{lll}
\hline Theme & Findings \\
\hline 1. Knowledge on nutrition management of CKD patients & $\cdot$ Inadequate training in medical schools \\
& $\cdot$ Lack of reference materials (books, internet) \\
3. Attitude on nutrition training in medical school $\quad$ Application of nutrition knowledge (practices) & $\cdot$ Lack of nutrition guidelines \\
& & $\cdot$ Lack of nutrition guidelines \\
4. Challenges on nutrition management of CKD patients & $\cdot$ Lack of reference materials \\
& $\cdot$ Inadequate nutrition training \\
& $\cdot$ Labour shortage \\
& $\cdot$ Lack of motivation \\
\hline
\end{tabular}

knowledge among licenced nurses working in nursing homes, it was also showed that there was a correlation between the educational substructure and the nutrition knowledge score[10]. Yalcin et al., [11] in their study on nutrition knowledge level of nurses in Zonguldaki in Turkey indicated that long-term clinical experience without any special education on nutrition and with no working experience in this field does not increase the nutrition knowledge.

In this study, healthcare workers scored high in questions that were medical related but they scored low in nutrition related questions (Table 2). This could be due to less emphasis on nutrition training in medical/nursing schools as mentioned during group discussion that nutrition knowledge they gained was not adequate to provide nutritional counselling and support to CKD patients (Table 5). These findings are consistent with other studies that showed the inadequacy of education regarding nutrition in medical and nursing programs and the requirement of expanded content of nutrition in the curricula [12, 13].

According to Kim [14], in the study on Nurses' positive attitudes to nutritional management but limited knowledge of nutritional assessment in Korea identified that limited education in nutrition could lead nurses to be negligent in managing patients' nutritional problems. This observation is important as it has been shown that nurses are a trusted source of health information as noted in the study by Harrison [15].

The lack of knowledge about nutrients (minerals, protein, and carbohydrate) adjustment is of particular concern, as there is growing interest on changes in disease patterns in relation to foods and nutrition [16]. Doctors and nurses are perceived to be the most reliable source of nutritional information. Therefore, it is important that information provided by health professionals is accurate. As found in this study that only few healthcare workers have the time, knowledge or skills to give nutritional advice or to recognize nutrition related problems, similar observation were found by other studies [14, 17].

Participants felt that nutrition plays an important role in prevention and treatment of disease. However, $72.4 \%$ of nurses reported that they were not knowledgeable in nutrition related matters and that nutrition assessment was the responsibility of nutritionists and doctors. In places where nutritionist services are not available as is common in most hospitals in Tanzania, nurses tend to fully depend on doctors for guidance as far as nutritional management of patients is concerned.

Furthermore, results indicated that $76.7 \%$ had negative attitude regarding their own nutritional knowledge. This was revealed when they were asked to rate themselves on nutrition related matters. This could be due to inadequate nutrition training in medical/nursing schools and as part of in-service trainings in patient care. Such negative attitudes were expressed during group discussion when they were asked to give opinion on nutrition knowledge in their professional training. Different studies have revealed that in-service nutrition training can help to improve health workers' nutrition knowledge $[18,19]$. This may facilitate positive changes in their attitudes toward nutrition care and thus in their behaviour $[19,20]$. As a result, health workers' skills in management of nutrition-related problems including nutritioncounselling skills [20-22].

According to Fischbein's learning theory, behaviour or attitude change is mediated through cognitive processes and thus is learned through imitating and observing the actions of others [20]. Accordingly, the reward that health workers can gain from their nutrition actions, 
such as better nutritional status or feeding practices in those they treat, may reinforce their counselling actions, thus making it a permanent habit. In this way, the quality of health workers with regard to nutrition counselling might be expected to improve.

In this study an assessment of a patient's nutritional condition was not always performed. Instead, the patient's condition, diagnosis, treatment and age were taken into consideration as criteria for diagnosis. The reasons might be found in inadequate knowledge and skills, or perceived lack of resources, such as assessment tools and guidelines (Table 5). These factors may also explain the finding of low frequencies of nutrition education sessions services, such as nutritional support (Table 4). Limited use of assessment tools confirmed by another study [21]. Another reason could be that the doctors use their clinical judgement and therefore abandon the nutrition assessment tools [21]. In addition, nurses assume that nutritional assessment is not part of their role, the fact which has been discussed recently [22].

\section{Limitations}

This study was conducted using intentional sampling of healthcare workers from a single municipality, and given the cultural particularities of this group, extrapolations of the finding $\mathrm{s}$ are limited. Furthermore, the study did not cover all medical conditions related to nutrition, and this is another limitation of this study.

\section{Conclusion}

As found in the present study, nutrition knowledge among study participants was poor. Despite their positive attitudes regarding nutrition and its importance, they failed to practice due to inadequate knowledge. Inadequate resources and inadequate nutrition training in medical/ nursing schools hindered proper nutrition management of CKD patients. Continuous in-service nutrition education programs, improving working conditions and hiring clinical nutritionists in each hospital department may improve nutrition management of CKD patients in hospitals.

\section{Abbreviations}

CKD: chronic kidney disease; ESRD: end stage renal disease; MUHAS: Muhimbili University of Health and Allied Sciences.

\section{Competing interest}

The authors declare that they have no competing interests.

\section{Authors' contributions}

AM participated in the concept on and design of the study and coordinated the da ta collection and analysis. BM and OK assisted in critically reviewing the proposal design of the study, and data analysis. GO critically reviewed the work, assisted in analysis and interpretation of the data. AM prepared the manuscript for publication. All authors read and approved the final manuscript.

\section{Acknowledgements}

The authors gratefully acknowledge the health workers who took part in this study, and the Ministry of Health and Social Welfare Tanzania for funding the study.

\section{Author details}

${ }^{1}$ Tanzania Food and Nutrition Centre, Dar es salaam, Tanzania. ${ }^{2}$ Dedan Kimathi University of Technology, Nyeri, Kenya. ${ }^{3}$ Muhimbili National Hospital, Dar es Salaam, Tanzania. ${ }^{4}$ School of Public Health, Kenyatta University, Nairobi, Kenya.

Received: 18 August 2015 Accepted: 12 January 2016

Published online: 16 January 2016

\section{References}

1. Olugbenga E, Ayodele C, Olutayo A. Burden of chronic kidney diseases. Peritoneal dialysis patients. J Ren Nutr I. 2010;20(3):193-8.

2. Sarnak MJ, Levey AS, Schoolwerth AC, Coresh J, Culleton B, Hamm LL, et al. Kidney disease as a risk factor for development of cardiovascular disease: A statement from the American Heart Association Councils on Kidney in Cardiovascular Disease, High Blood Pressure Research, Clinical Cardiology, and Epidemiology and Prevention. Hypertension. 2003:42:1050-65.

3. Moore H, Reams SM, Wiesen K, Nolph KD, Khanna R, Laothong C. National Kidney Foundation Council of renal nutrition survey: past- present clinical practices and future strategic planning. J Ren Nutr. 2003;13(3):233-40.

4. Kris-Etherton PM, Akabas SR, Bales CW, Bistrian B, Braun L, Edwards MS, et al. The need to advance nutrition education in the training of health care professionals and recommended research to evaluate implementation and effectiveness. Am J Clin Nutr. 2014:99(suppl):1153S-66S.

5. Rosen BS, Maddox P, Ray N. A position paper on how cost and quality reforms are changing healthcare in America: focus on nutri-tion. JPEN J Parenter Enteral Nutr. 2013;37:796-8016.

6. World Health Organization.(2003). Diet, Nutrition and the Prevention of Chronic Diseases. Geneva: World Health Organization;:Available from: http://whqlibdoc.who.int/trs/who trs916.pdf. Accessed December 1, 2013

7. Bjerrum M, Tewes M, Pedersen P. Nurses' self-reported knowledge about and attitude to nutrition before and after a training programme. Scand Carin Sci. 2011;26(1):81-9. doi:10.1111/j.1471-6712.00906.x.

8. DiMaria-Ghalili RA, Mirtallo JM, Tobin BW, Hark L, Van Horn L, Palmer CA. Challenges and opportunities for nutrition education and training in the health care professions: intraprofessional and interprofessional call to action. Am J Clin Nutr. 2014;99(suppl):1184S-93.

9. United Republic of Tanzania (2012). Population Census [http://www tanzania.tz//census.html]. Site visited on 22/03/ 2013

10. Crogan N, Evans B. Nutrition assessment: Experience is not a predictor of knowledge. J Contin Educ Nurs. 2001:32(5):219.

11. Yalcin N, Cihan A, Gundogdu H, Ocakci A. Nutrition knowledge level of nurses. Health Sci J. 2013:7(1):99-108.

12. Yfanti E, Tsiriga S, Yfantis A, Tiniakou I, Mastrapa E. Nutrition knowledge in students of a Nursing School. Health SCI J. 2011;5(2):118-27.

13. Martin Kohlmeier, Caryl A. Nowson, Rose Ann DiMaria-Ghalili, and Sumantra Ray (2015) Nutrition Education for the Health Care Professions. Journal of Biomedical Education. p 2

14. Kım H, Choue R. Nurses' positive attitudes to nutritional management but limited knowledge of nutritional assessment in Korea. Int Nurs Rev. 2009;56(3):333-9.

15. Harrison GG. Public health interventions to combat micronutrient deficiencies. Publ Health Rev. 2010;32:256-66.

16. Stark CM, Graham-Kiefer ML, Devine CM, Dollahite JS, Olson CM. Online course increases nutrition professionals' knowledge, skills, and self-efficacy in using an ecological approach to prevent childhood obesity. J Nutr Educ Behav. 2011;43(5):316-22. doi:10.1016/j.jneb.01.010.

17. Leslie FC, Thomas S. Competent to care. Are all doctors competent in nutrition? Proc Nutr Soc. 2009;68(3):296-9. doi:10.1017/S0029665109001293.

18. Fletcher A, Carey E. Knowledge, attitudes and practices in the provision of nutritional care. Br J Nurs. 2011;20(10):615-6.

19. Perry L. Nutrition: a hard nut to crack. An exploration of the knowledge, attitudes and activities of qualified nurses in relation to nutritional nursing care. J Clin Nurs. 1997:6(4):315-24.

20. Fishbein M, Ajzen I. Belief formation. In: Fishbein M, Ajzen I, editors. Belief, attitude, intention, and behavior: an introduction to theory and research. Reading: Addison-Wesley; 1975. p. 130-215. 
21. Lindorff-Larsen K, Højgaard Rasmussen H, Kondrup J, Staun M, Ladefoged K, Group SN. Management and perception of hospital undernutrition a positive change among Danish doctors and nurses. Clin Nutr. 2007;26(3): 371-8. doi:10.1016/j.clnu.01.006.

22. Jefferies $D$, Johnson $M$, Ravens J. Nurturing and nourishing: the nurses' role in nutritional care. J Clin Nurs. 2011:20(3-4):317-30.

Submit your next manuscript to BioMed Central and we will help you at every step:

- We accept pre-submission inquiries

- Our selector tool helps you to find the most relevant journal

- We provide round the clock customer support

- Convenient online submission

- Thorough peer review

- Inclusion in PubMed and all major indexing services

- Maximum visibility for your research

Submit your manuscript at www.biomedcentral.com/submit 